\title{
Effects of Antenatal Betamethasone Administration on Fetal Heart Rate and Behavior in Twin Pregnancy
}

\author{
EDUARD J.H. MULDER, JAN B. DERKS, AND GERARD H.A. VISSER \\ Department of Perinatology and Gynecology, Wilhelmina Children's Hospital, Lundlaan 6, 3584 EA, \\ University Medical Center, Utrecht, The Netherlands
}

\begin{tabular}{|c|c|}
\hline \multicolumn{2}{|c|}{ ABSTRACT } \\
\hline $\begin{array}{l}\text { The efficacy of antenatal corticosteroid therapy in reducing } \\
\text { the incidence of respiratory distress syndrome in twin pregnancy } \\
\text { is controversial. The corticosteroid levels achieved with the } \\
\text { current regimen might not be high enough to reach both siblings. } \\
\text { In singleton fetuses, maternal betamethasone administration } \\
\text { causes transient reductions in fetal heart rate (FHR), FHR vari- } \\
\text { ability, and body and breathing movements. We performed a } \\
\text { prospective study to determine whether there are similar effects } \\
\text { of betamethasone on FHR and behavior in preterm twin preg- } \\
\text { nancy and whether the effects occur similarly in both twin } \\
\text { members. Eighteen women who were carrying twins received } \\
\text { optimal corticosteroid treatment. Simultaneous recordings were } \\
\text { made on twins before (day } 0 \text { ), during (days } 1-2 \text { ), and after (days } \\
3-4 \text { ) corticosteroid therapy using separate cardiotocography and } \\
\text { ultrasound machines. Betamethasone administration was associ- } \\
\text { ated with significant transient decreases in basal FHR (day } 1 \text { ), } \\
\text { FHR variability (days } 2 \text { and } 3 \text { ), and body and breathing move- } \\
\text { ments (day } 2 \text { ). The overall changes in twins were similar to those } \\
\text { previously found in singleton pregnancies. There was a high }\end{array}$ & $\begin{array}{l}\text { degree of association of response to betamethasone among indi- } \\
\text { vidual members of twin pairs. The betamethasone-induced ef- } \\
\text { fects were unrelated to fetal sex, positioning, chorionicity, and } \\
\text { discordance in size, but there was an effect of gestation on FHR. } \\
\text { We conclude that the current regimen of antenatal corticosteroids } \\
\text { used in preterm twin pregnancies results in observable physio- } \\
\text { logic and behavioral changes in twin pairs irrespective of their } \\
\text { composition. This provides evidence that the achieved beta- } \\
\text { methasone levels are high enough to reach the compartment of } \\
\text { either twin member. (Pediatr Res 56: 35-39, 2004) } \\
\text { AGA, appropriate in size for gestational age } \\
\text { FHR, fetal heart rate } \\
\text { GA, gestational age } \\
\text { GM, generalized fetal body movements } \\
\text { LTV, long-term variability } \\
\text { SGA, small for gestational age }\end{array}$ \\
\hline
\end{tabular}

Antenatal corticosteroid therapy is widely used to mature the fetal lung in pregnancies that are likely to end before $34 \mathrm{wk}$. It reduces the incidence of respiratory distress syndrome and results in an overall improvement in neonatal morbidity and mortality $(1,2)$. However, the beneficial effects of corticosteroids seem to be reserved for preterm singleton gestations, as similar improvements in twin pregnancies have not been demonstrated (2-5), occurred to a lesser extent, or were limited to specific subgroups (5-7). Several factors may account for the putative difference in efficacy of antenatal corticosteroid treatment between twin and singleton pregnancies. It has recently been found that the half-life of betamethasone is shorter and its clearance is greater in twin pregnancy than in singleton preg-

Received June 3, 2003; accepted December 31, 2003

Correspondence: Eduard J.H. Mulder, Ph.D., Department of Perinatology and Gynecology, KE.04.123.1, Wilhelmina Children's Hospital, Lundlaan 6, 3584 EA, Utrecht, The Netherlands; e-mail: emulder@azu.nl

DOI: 10.1203/01.PDR.0000130476.97700.2B nancy (8). In addition, women who carry twins have a larger volume of distribution $(3,4)$. This raises the question of whether the plasma levels of synthetic corticosteroids that are achieved with the current drug regimen in twin pregnancy are high enough to reach both siblings. Studying the physiologic response to corticosteroids in both fetuses may provide an answer to this question.

In singleton pregnancies, considerable but transient reductions in fetal heart rate (FHR), FHR variability, and movements occur 1-3 d after the first dose of betamethasone (9-17). Previous studies have suggested similar reductions to occur in twin pregnancies, but they lack information on twin inter-pair and intra-pair responsiveness to corticosteroids (12-15). Dawes et al. (12) reported differential fetal response to dexamethasone exposure in a single case of discordant twin pregnancy complicated by Doppler abnormalities in the smaller fetus. Besides growth discordance, other factors associated with poor outcome of twin pregnancy, including monochorionicity, prematurity (length of gestation), and male sex (the male-male cohabitation in particular) might also 
affect the fetal response to antenatal corticosteroids $(6,18)$. The objective in this study was to investigate whether fetal responsiveness to betamethasone is similar in singleton and twin pregnancies and whether the drug-induced effects are similar in both twin members.

\section{METHODS}

Subjects. We conducted a prospective study of the fetal effects of maternal betamethasone administration in twin pregnancies. The study had local research ethics board approval, and all patients gave informed consent. Eighteen women who were carrying monochorionic $(n=7)$ or dichorionic $(n=11)$ twin pregnancies at 26-32 wk (median, $29 \mathrm{wk}$ ) of gestational age (GA) and were at high risk for preterm delivery participated in the study. Maternal age varied between 25 and $41 \mathrm{y}$ (median, 32 y). Twelve women were nulliparous. There were 12 spontaneously conceived pregnancies, and 6 twin pregnancies had resulted from in vitro fertilization. Indications for steroid administration were small for gestational age (SGA; estimated fetal size $<5$ th percentile) with or without preeclampsia $(n=13)$, threatened preterm labor $(n=3)$, placenta previa or other causes of vaginal blood loss $(n=1)$, or preterm rupture of the membranes without clinical evidence of intrauterine infection $(n=1)$. Exclusion criteria were cervical dilation $>5 \mathrm{~cm}$, signs of intrauterine infection, or treatment with tocolytic drugs (ritodrine hydrochloride) for $\leq 5 \mathrm{~d}$ from the start of the study. All patients received a full course of steroids defined as two doses of $12 \mathrm{mg}$ of betamethasone i.m. (Celestone Chronodose, Schering-Plough, Weesp, The Netherlands), $24 \mathrm{~h}$ apart. Two women received a second course of betamethasone $2 \mathrm{wk}$ later and were included again. All patients were in a stable clinical condition, and medication when used at the start of the study was not changed during the $5 \mathrm{~d}$. The median interval between the start of therapy and delivery was 3 wk (range, 1-7 wk).

Median gestational age at delivery was $31^{5 / 7}$ weeks (range, $28^{1 / 7}-38^{1 / 7}$ ); 14 women were delivered by cesarean section. There were seven pairs of male-male twins, six pairs of female-female twins, and five twin pairs of unlike sex, resulting in a total of 19 boys and 17 girls. There were two pregnancies in which one of the fetuses died in utero (at $30^{1 / 7}$ and $33^{3 / 7}$ wk GA); fetal death occurred 10 and $24 \mathrm{~d}$ after the first dose of betamethasone, respectively. Median birth weight of the live-born infants was $1660 \mathrm{~g}$ (range, 650-2670 g). The intra-pair discrepancy in birth weight was calculated as the difference in weight (largest minus smallest) divided by the weight of the largest infant multiplied by 100 . Nine pairs had a birth weight difference of $>20 \%$. SGA was defined as a birth weight at $<10$ th percentile according to the Dutch birth weight charts adjusted for gestational age, parity, and sex (19). There were 10 twin pairs in which both fetuses were appropriate in size for gestational age (AGA), 1 pair in which both fetuses were SGA, and 7 pairs in which 1 twin was AGA and the co-twin was SGA; thus, 9 fetuses were SGA. In three of the SGA fetuses, there were Doppler abnormalities defined as absent or reversed end diastolic flow. Vascular anastomoses could be demonstrated in the placentas of three monochorionic twins. Both members of one of these twin pairs died in the first week after birth. All other infants did well in the neonatal period.

The sample size calculation was based on the expected differences in fetal parameters on day 2 of the study that were reported previously to be substantial in singleton pregnancies $(10,11)$. At $\alpha=0.05$ and a power of $80 \%$, the study required 17 subjects to demonstrate a $15 \%$ reduction in heart rate variability, 11 subjects to show a $40 \%$ reduction in body movements, and 13 subjects to evaluate a $80 \%$ reduction in breathing activity.

Procedure. The study period comprised 5 successive days (days $0-4$ ). Betamethasone was administered on day 0 after baseline recordings of FHR and movements had been made earlier that day and again $24 \mathrm{~h}$ later (day 1). Simultaneous recordings of FHR were made on twins daily using two separate cardiotocograph machines (Hewlett Packard 8040A, Böblingen, Germany) each connected to a computer running the System 8002 program for on-line FHR analysis (Oxford Sonicaid, Chichester, U.K.) (20). With this program, basal FHR and pulse-interval differences were determined. FHR long-term variability (LTV) was calculated as the average of 1-min pulse-interval differences, whereas FHR short-term variation (STV) was calculated as the average of $1 / 16$ min pulseinterval differences (21). Decelerations were excluded from analysis. There were 20 complete sets of FHR records; recording lasted for $40 \mathrm{~min}$ (median; range, 36-60 min; $n=100$ records). The time of day of recording (between 1000 and $1500 \mathrm{~h}$ ) was standardized per patient, thus ruling out the possible influence of maternal meals and diurnal rhythms.

In a subgroup of 14 patients, simultaneous recordings of fetal behavior were made on twins on days 0,2 , and 4 of the study period $(n=15$ sets of observation as one patient participated twice). Median observation time was $60 \mathrm{~min}$ (range, $40-60$ min; $n=45$ records). Fetal body and breathing movements were visualized by two observers each studying a particular fetus with the use of real-time ultrasonography. Their position on the patients' left or right side was randomized at the start of each study period and remained unchanged on the following days. Fetal movements were recorded on-line and stored into a computer. Generalized body movements (GM) occurring within $1 \mathrm{~s}$ apart were regarded a single burst (9-11). Bouts of continuous breathing activity were registered when the intervals between consecutive breaths were $\leq 6 \mathrm{~s}$. The incidence of these movement patterns was expressed as a percentage of observation time. In addition, profiles of longterm presence or absence of fetal body movements were drawn up using a 3-min moving window procedure (22). The following parameters of the fetal rest-activity cycle were calculated for each recording: the time spent in quiescence ( $\%$ incidence) and the longest episode of rest (min). Recordings of FHR and behavior that had been obtained from 63 women who had singleton pregnancies and were at high risk for preterm delivery and received betamethasone between 26 and 34 wk served for comparison (9-11).

Statistical analysis. Data are presented as medians (interquartile ranges). Groups were compared using the MannWhitney $U$ test. All fetal parameters had (near) normal distributions. The FHR and movement parameters were analyzed 
using ANOVA with repeated measures on time (days of study), and the effects of potential covariates (dichotomized) were evaluated. Significant $F$ ratios $(p<0.05)$ were followed with post hoc contrast comparisons (Dunnett test). Twin intra-pair relationships were studied by means of Pearson correlation analysis. Statistical analyses were performed using SPSS version 10.1 (SPSS Inc., Chicago, IL, U.S.A.). With all tests, significance was assumed at the level of $p<0.05$ (two-tailed).

\section{RESULTS}

For the total group of twins, all fetal parameters showed a significant change during the study period (Table 1). Betamethasone administration was associated with significant decreases in basal FHR (day 1), LTV (days 2 and 3), short-term variability (day 2), and body and breathing movements (day 2), whereas the fetuses spent more time in quiescence as a result of prolonged episodes of rest (day 2). The overall changes in twins were similar to those previously found in singleton pregnancies (Table 1). To explore the effects of covariates on the drug-induced changes, we performed analyses on twins considered as individuals (between pairs) and pair-wise.

Comparison of fetal responsiveness to betamethasone between pairs of twins. Repeated measures ANOVA did not reveal any significant main Group effect or time $\times$ group interaction for fetal sex (male versus female), positioning (left versus right), chorionicity, and growth discordance $(\leq 20 \%$ versus $>20 \%$ ). Basal FHR showed a differential time course between the fetuses recorded before $29 \mathrm{wk}$ GA and those after 29 wk GA $[F(4,35)=4.0, p=0.004, n=20$ versus $n=20]$, with a reduction in FHR on day 1 in the older fetuses $(p<0.05$ versus baseline) but no change over time in the younger fetuses. The time courses of the other parameters did not attain statistical significance for the older versus younger fetuses.

Comparison of fetal responsiveness to betamethasone within pairs of twins. To explore twin intra-pair differences in responsiveness to betamethasone, we plotted for each pair the change in a particular parameter that occurred in the leftpositioned fetus against that of the co-twin on the right side of the uterus. There was a high degree of association of response to betamethasone among individual members of twin pairs. This is shown for the percentage change in FHR on day $1(R$ $=0.72, p<0.001, n=20$; Fig. 1 ), the percentage changes in LTV on days 2 and $3(R=0.63, p=0.003$, and $R=0.69, p$ $=0.001, n=20$, respectively; Fig. 2), the percentage change in GM on day $2(R=0.62, p=0.016, n=15$; Fig. 3$)$, and the absolute changes in fetal quiescence $(R=0.36, p>0.05, n=$ $15)$ and breathing activity on day $2(R=0.72, p=0.002, n=$ 15; Fig. 4). Thus, the response to betamethasone in the one fetus was highly predictive of that in the co-twin. This was independent of gender cohabitation, chorionicity, or cohabitation of appropriately grown fetuses (AGA-AGA) or fetuses discordant in size (SGA-AGA). In addition, the fetuses who were destined subsequently to die (either in utero or after birth) and those with Doppler abnormalities or placental vascular anastomoses showed responses to betamethasone that were indistinguishable among the data points in the scatter diagrams (data not shown).

\section{DISCUSSION}

This study demonstrated similar overall responsiveness to maternal betamethasone administration in singleton and twin pregnancies. During drug therapy, we observed transient decreases compared with baseline (day 0) for basal FHR (day 1), FHR variability (days 2 and 3), and body and breathing movements (day 2). The reduction in body movements resulted from a betamethasone-induced effect on the ultradian restactivity cycle as indicated by an increase in fetal quiescence and prolonged episodes of uninterrupted rest (day 2). Both the direction and the magnitude of change in these parameters

Table 1. Effect of betamethasone administration on fetal heart rate and movement parameters during the study period (3 or 5 d) as determined by one-way ANOVA for repeated measures (F statistic)

\begin{tabular}{|c|c|c|c|c|c|}
\hline \multirow[b]{2}{*}{ Parameter } & \multicolumn{2}{|c|}{ Repeated measures ANOVA } & \multicolumn{3}{|c|}{ Change from baseline [median (IQR)] } \\
\hline & $F$ & Contrast & Twins & Singletons & $p$ \\
\hline Fetal heart rate (bpm; $n=40)$ & $\begin{array}{c}F(4,36)=4.6 \\
p<0.002\end{array}$ & day $0-1 *$ & -1.7 ( -6 to 2$) \%$ & $-2.1(-5$ to 1$) \%$ & 0.14 \\
\hline $\operatorname{LTV}(\mathrm{ms} ; n=40)$ & $\begin{array}{c}F(4,36)=6.6 \\
p<0.0001\end{array}$ & $\begin{array}{l}\text { day } 0-2^{*} \\
\text { day } 0-3^{*}\end{array}$ & $\begin{array}{l}-13.9(-28 \text { to } 7) \% \\
-11.7(-29 \text { to } 3) \%\end{array}$ & $\begin{array}{l}-18.8(-33 \text { to }-3) \% \\
-13.2(-24 \text { to }-3) \%\end{array}$ & $\begin{array}{l}0.33 \\
0.67\end{array}$ \\
\hline Short-term FHR variation $(\mathrm{ms} ; n=40)$ & $\begin{array}{c}F(4,36)=7.0 \\
p<0.0001\end{array}$ & day $0-2 *$ & $-14.2(-29$ to 15$) \%$ & $-15.6(-33$ to -3$) \%$ & 0.31 \\
\hline Fetal quiescence $(n=30)$ & & & & & \\
\hline Incidence (\% of time) & $\begin{array}{c}F(2,28)=10.7 \\
p<0.0001\end{array}$ & day $0-2 \dagger$ & 21.1 (5 to 37$)$ & $20.2(1$ to 40$)$ & 0.99 \\
\hline Longest episode (min) & $\begin{array}{c}F(2,28)=12.3 \\
p<0.0001\end{array}$ & day $0-2 \dagger$ & $13 \quad(0$ to 18$)$ & $9.5(3$ to 19$)$ & 0.79 \\
\hline
\end{tabular}

$* p<0.05$.

$\dagger p<0.01$.

Contrast indicates a significant difference between day 0 and each of the four other days (Dunnett post hoc test). The direction and magnitude of change from baseline (\% or absolute change) are indicated separately for twin and singleton pregnancies and were tested for significance with the Mann-Whitney $U$ test. IQR, interquartile range. 


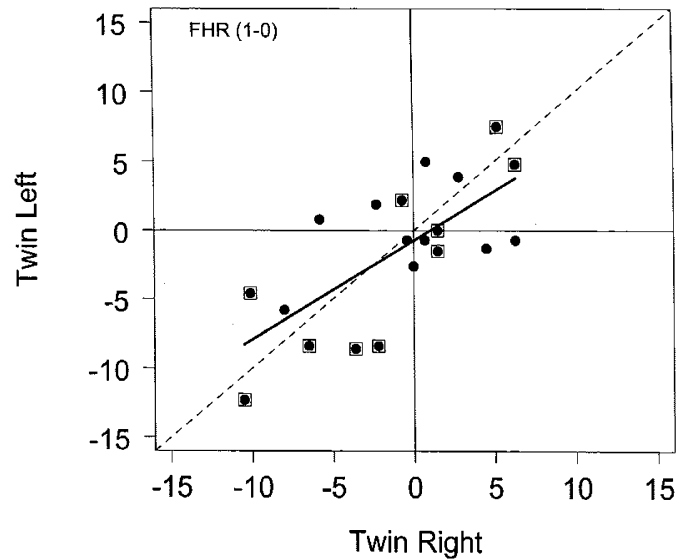

Figure 1. Twin-twin correlations for the percentage changes in basal FHR on day $1 v s$ baseline between left- and right-positioned fetuses. Cohabitation of a small and appropriately grown fetus is indicated (SGA-AGA pair). The line of equality is presented as dashed line. See text for $R$ and $p$ values.

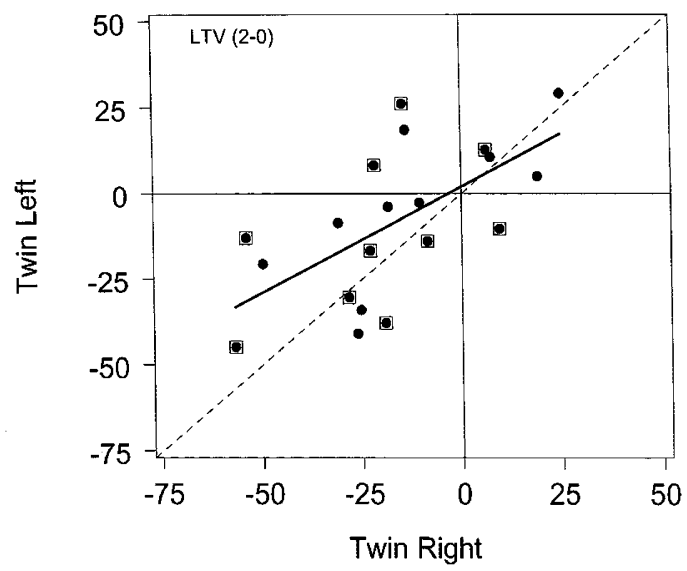

Figure 2. Twin-twin correlations for the percentage changes in LTV on day 2 vs baseline between left- and right-positioned fetuses. Cohabitation of a small and appropriately grown is indicated (SGA-AGA pair). The line of equality is presented as dashed line. See text for $R$ and $p$ values.

("fetal response") were similar to and not significantly different from those previously found in singleton pregnancy (9-11).

The mechanisms underlying the effects of betamethasone on the studied fetal parameters are still unclear (11). The reduction in FHR may be secondary to a betamethasone-induced increase in fetal blood pressure triggered by the baroreceptor reflex. The behavioral effects of betamethasone and its effect on FHR variability might be the result of glucocorticoid receptormediated processes in brainstem nuclei that control the alternation between episodes of fetal rest and activity. Before $34 \mathrm{wk}$ GA, these episodes are already fairly associated with tracings of low and high FHR variability, respectively (23).

The drug-induced alterations are suggestive of fetal distress and may lead to unnecessary iatrogenic preterm delivery (9). However, we have previously shown that fetal hypoxia as a result of antenatal corticosteroid treatment is unlikely to occur $(24,25)$. Transient reductions in heart rate and GM have also been found in preterm infants with bronchopulmonary dysplasia during the first week of postnatal dexamethasone therapy $(26,27)$. Awareness of the possible drug side effects is essential

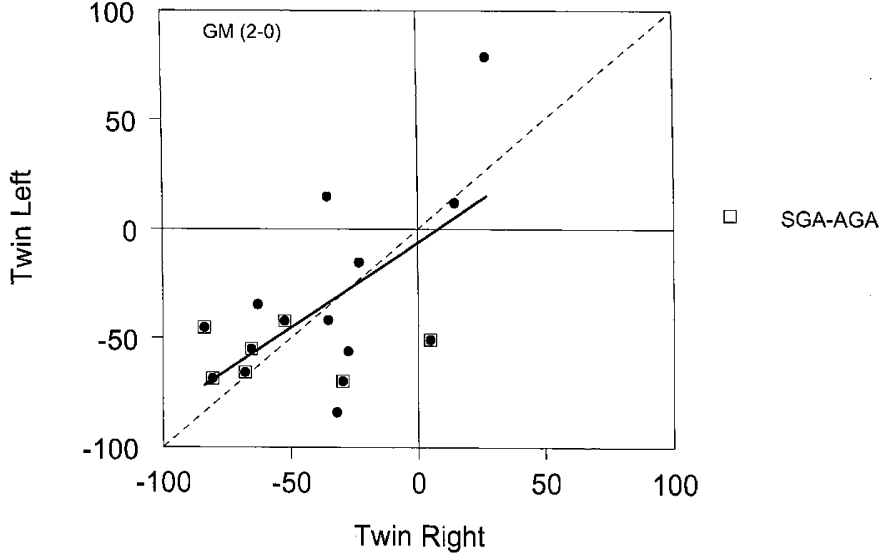

Figure 3. Twin-twin correlations for the percentage changes in the incidence of GM on day 2 vs baseline between left- and right-positioned fetuses. Cohabitation of a small and appropriately grown fetus is indicated (SGA-AGA pair). The line of equality is presented as dashed line. See text for $R$ and $p$ values.

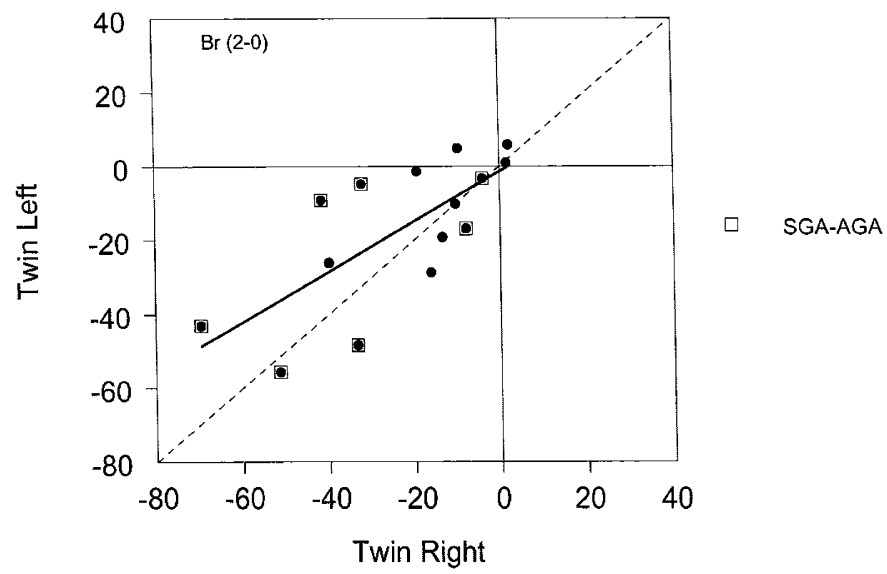

Figure 4. Twin-twin correlations for the absolute changes in the incidence of fetal breathing movements $(\mathrm{Br})$ on day $2 \mathrm{vs}$ baseline between left- and right-positioned fetuses. Cohabitation of a small and appropriately grown is indicated (SGA-AGA pair). The line of equality is presented as dashed line. See text for $R$ and $p$ values.

as their occurrence may influence clinical decision making in this group of infants.

Among twin pairs, the responses to betamethasone were generally concordant in either twin member. A concerted response was seen even when the direction of change in a fetal parameter was opposite of that expected (Figs. 1-4). There were no evident modifying effects of gender cohabitation (male-male, femalefemale, female-male twins), cohabitation of appropriately grown fetuses or fetuses discordant in size, chorionicity, and the presence of Doppler abnormalities or placental vascular anastomoses. The general finding of a strong intra-pair concordance for betamethasone responsiveness does not support the single observation by Dawes et al. (12), who reported a differential FHR response to dexamethasone between the AGA fetus and its SGA co-twin of a discordant twin pair.

Unlike the high degree of concordance within twin pairs, the variation in fetal response to betamethasone between twin pairs was considerable. Previous results have indicated no role for maternal age, parity, type of pregnancy (spontaneous versus 
fertility-assisted), reason for corticosteroid treatment, fetal sex, and growth restriction in determining some of the variation in fetal response among singletons (11). Our findings in twins are in agreement, although the small numbers of fetuses from some subgroups of twin pregnancies do not permit firm conclusions as yet. However, some evidence was found for gestationdependent effects of betamethasone on FHR (significant) and body movements, as the twin pairs who did not show a decrease in GM had been recorded before 29 wk GA (Fig. 3). These observations are in line with recent findings in singleton pregnancies in which reductions in basal FHR and body movements occurred almost exclusively when betamethasone was administered at 29-34 wk GA but not earlier (11). In the current study, an age-related effect on GM may have gone unnoticed statistically because of small sample size and few recordings made at the extremes of the age range (none were made after 32 wk GA).

A sample of twins allows distinguishing between influences that affect both twins and influences that are unique to either twin member. Twins share the same maternal environment, including disease status, pharmacokinetics of drugs, and GA. Nevertheless, each twin half has its own fetoplacental environment as reflected, for instance, by its birth weight, which may differ substantially within a pair as a result of discordance in placental "sufficiency." We found no evidence of impaired access of betamethasone to the compartment of the smaller compared with the larger fetus of discordant twin pairs. Thus, morphologic and functional factors presumed to underlie placental insufficiency and reduced supply of oxygen and nutrients to the smaller fetus did not seem to affect transplacental passage of betamethasone.

Gestation at betamethasone administration was found to be a factor of some importance in determining the extent of druginduced changes. Both maternal and placental pharmacokinetic properties for betamethasone may depend on gestation, but no one has investigated this (11). However, there is evidence from animal experiments that age-related effects of corticosteroids are of fetal origin $(28,29)$. We therefore recently hypothesized that the differences in response to betamethasone for younger versus older fetuses may relate to ontogenic changes in glucocorticoid receptor maturation, to developmental changes in the cardiovascular and nervous systems, or to a combination of these (11).

The present findings on twins demonstrated that the use of two doses of $12 \mathrm{mg}$ of betamethasone given $24 \mathrm{~h}$ apart generally results in observable changes in fetal physiology and behavior. This occurred similarly in either member of a twin pair irrespective of its composition, indicating that the levels of betamethasone are sufficiently high to reach both twin members and to exert their effects on fetal functioning. Beneficial effects of betamethasone on fetal lung maturation might be anticipated under these circumstances. Our results, although providing indirect evidence, do not support the suggestion made by others that the achieved level of betamethasone is subtherapeutic for lung maturation in twin pregnancy (8). However, there is evidence from twin studies that corticosteroids effectively reduce the incidence of respiratory distress syndrome in the 28- to 32- but not the 24- to 27-wk GA ranges (6). These findings also point to developmental changes in the fetus rather than to inefficiency of the current steroid regimen.
There is currently no need to reconsider the total dose, route, timing, and rate of administration for corticosteroids in twin pregnancy, as was previously suggested $(2,4)$.

\section{REFERENCES}

1. NIH Consensus Development Conference 1995 Effects of corticosteroids for fetal maturation on perinatal outcomes. JAMA 273:413-418

2. Crowley P 2003 Prophylactic corticosteroids for preterm birth (Cochrane review). In: The Cochrane Library, Issue 4. J. Wiley \& Sons, Chichester, UK

3. Burkett G, Bauer CR, Morrison JC, Curet LB 1986 Effect of prenatal dexamethasone administration on prevention of respiratory distress syndrome in twin pregnancies. J Perinatol 6:304-308

4. Turrentine MA, Dupras-Wilson P, Wilkins IA 1996 A retrospective analysis of the effect of antenatal steroid administration on the incidence of respiratory distress syndrome in preterm twin pregnancies. Am J Perinatol 13:351-354

5. Quist-Therson EC, Myhr TL, Ohlsson A 1999 Antenatal steroids to prevent respiratory distress syndrome: multiple gestation as an effect modifier. Acta Obstet Gynecol Scand 78:388-392

6. Ardila J, Le Guennec J-C Papageorgiou A 1994 Influence of antenatal betamethasone and gender cohabitation on outcome of twin pregnancies 24 to 34 weeks of gestation. Sem Perinatol 18:15-18

7. Hacking D, Watkins A, Fraser S, Wolfe R, Nolan T 2001 Respiratory distress syndrome and birth order in premature twins. Arch Dis Child Fetal Neonatal Ed. 84:F117-F121

8. Ballabh P, Lo ES, Kumari J, Cooper TB, Zervoudakis I, Auld PAM, Krauss AN 2002 Pharmacokinetics of betamethasone in twin and singleton pregnancy. Clin Pharmacol Ther 71:39-45

9. Derks JB, Mulder EJH, Visser GHA 1995 The effects of maternal betamethasone administration on the fetus. Br J Obstet Gynaecol 102:40-46

10. Mulder EJH, Derks JB, Visser GHA 1997 Antenatal corticosteroid therapy and fetal behavior: a randomised study of the effects of betamethasone and dexamethasone. Br J Obstet Gynaecol 104:1239-1247

11. Mulder EJH, Koenen SV, Blom I, Visser GHA 2004 The effects of betamethasone on fetal heart rate and behavior depend on gestational age. Early Hum Dev 76:65-77

12. Dawes GS, Serra-Serra V, Moulden M, Redman CWG 1994 Dexamethasone and fetal heart rate variation. Br J Obstet Gynaecol 101:675-679

13. Ville Y, Vincent Y, Tordjman N, Hue MV, Fernandez H, Frydman R 1995 Effect of betamethasone on the fetal heart rate pattern assessed by computerized cardiotocography in normal twin pregnancies. Fetal Diagn Ther 10:301-306

14. Multon O, Senat M-V, Minoui S, Hue M-V, Frydman S, Ville Y 1997 Effect of antenatal betamethasone and dexamethasone administration on fetal heart rate variability in growth-retarded fetuses. Fetal Diagn Ther 12:170-177

15. Senat M-V, Minoui S, Multon O, Fernandez H, Frydman S, Ville Y 1998 Effect of dexamethasone and betamethasone on fetal heart rate variability in preterm labour: a randomised study. Br J Obstet Gynaecol 105:749-755

16. Rotmensch S, Liberati M, Celentano C, Efrat Z, Bar-Hava I, Kovo M, Golan A, Moravski G, Ben-Rafael Z 1999 The effect of betamethasone on fetal biophysical activities and Doppler velocimetry of umbilical and middle cerebral arteries. Acta Obstet Gynecol Scand 78:768-773

17. Subtil D, Tiberghien P, Devos P, Therby D, Leclerc G, Vaast P, Puech F 2003 Immediate and delayed effects of antenatal corticosteroids on fetal heart rate: a randomized trial that compares betamethasone acetate and phosphate, betamethasone phosphate, and dexamethasone. Am J Obstet Gynecol 188:524-531

18. Sherer DM 2001 Adverse perinatal outcome of twin pregnancies according to chorionicity: review of the literature. Am J Perinatol 18:23-37

19. Kloosterman GJ 1970 On intra-uterine growth. Int J Gynecol Obstet 8:895-912

20. Dawes GS, Moulden M, Redman CWG 1991 System 8000: computerized antenatal FHR analysis. J Perinat Med 19:47-51

21. Nijhuis IJM, ten Hof J, Mulder EJH, Nijhuis JG, Narayan H, Taylor DJ, Visser GHA 1998 Numerical fetal heart rate analysis: nomograms, minimal duration of recording, and intrafetal consistency. Prenat Neonat Med 3:314-322

22. Mulder EJH, O’Brien MJ, Lems YL, Visser GHA, Prechtl HFR 1990 Body and breathing movements in near-term fetuses and newborn infants of type-1 diabetic women. Early Hum Dev 24:131-152

23. Visser GHA, Poelmann-Weesjes G, Cohen TMN, Bekedam DJ 1987 Fetal behavior at 30 to 32 weeks of gestation. Pediatr Res 22:655-658

24. Cohlen BJ, Stigter RH, Derks JB, Mulder EJH, Visser GHA 1996 Absence of significant haemodynamic changes in the uterus following maternal betamethasone administration. Ultrasound Obstet Gynaecol 8:252-255

25. Derks JB, Giussani DA, Jenkins SL, Wentworth RA, Visser GHA, Padbury JF, Nathanielsz PW 1997 A comparative study of cardiovascular, endocrine and behavioural effects of betamethasone and dexamethasone administration to fetal sheep. J Physiol 499:217-226

26. Bos AF, van Asperen RM, van Eykern LA, Zijlstra WG, Okken A 1994 Heart rate, heart rate variability and metabolic rate in preterm infants with bronchopulmonary dysplasia in the first week of dexamethasone treatment. J Physiol 479:P23-P24

27. Bos AF, Martijn A, van Asperen RM, Hadders-Algra M, Okken A, Prechtl HFR 1998 Qualitative assessment of general movements in high-risk preterm infants with chronic lung disease requiring dexamethasone therapy. J Pediatr 132:300-306

28. Matthews SG 2000 Antenatal glucocorticoids and programming of the developing CNS. Pediatr Res 47:291-300

29. Stonestreet BS, Sadowska GB, McKnight AJ, Patlak C, Petersson KH 2000 Exogenous and endogenous corticosteroids modulate blood-brain barrier development in the ovine fetus. Am J Physiol Regul Integr Comp Physiol 279:R468-R477 